\title{
SATISFACTION WITH BANK BRANDS AMONG INDIVIDUAL USERS OF DEPOSIT SAVINGS
}

\author{
Ai Tran Huu \\ Dao Mai Thi Hong \\ Thu Nguyen Thi Mong \\ Van Hien University, Ho Chi Minh, Vietnam
}

Our survey-based study is aimed to find the influence of the following important factors: overall service quality, brand reputation, social responsibility, and customer satisfaction, in which overall service quality factor seems to have the most impact on satisfaction. The satisfaction factor has a substantial and positive effect on brand loyalty without the impact of regulatory variation. These two variables regulate conversion costs and commitment in the relationship that have a positive impact on the transition from brand satisfaction to brand loyalty, including behavioral loyalty and attitude loyalty.

Keywords: deposit savings; individual customers; bank brand loyalty

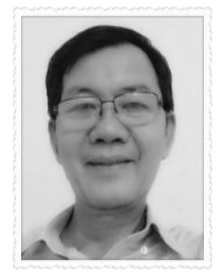

\section{Ai Tran Huu}

$\mathrm{PhD}$, lecturer of Faculty of Economics, Van Hien University, Ho Chi Minh City, Vietnam Research interests - markets of agricultural products, SMEs functioning and government support, organic food markets, ecological economics, environmental issues of economic development and corporate social responsibility Published more than 60 papers in International journals, member of editorial board of International journals

E-mail: aith@vhu.edu.vn

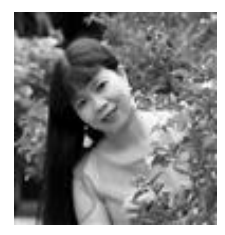

\section{Dao Mai Thi Hong}

MBA, Lecturer of Faculty of Economics, Van Hien University, Ho Chi Minh City, Vietnam Research interests: SMEs functioning and government support, consumer behavior, innovative products markets and finances. Published more than 20 papers in International journals.

E-mail: daomth@vhu.edu.vn

\section{Thu Nguyen Thi Mong}

Lecturer of Faculty of Economics, Van Hien University, Ho Chi Minh City, Vietnam Research interests: SMEs functioning and government support, consumer behavior, innovative products markets and finances.

E-mail: aith@vhu.edu.vn 


\section{Introduction}

Stability and development of an economy is the first decisive factor for the potential depositors to decide whether to send money to banks, to hoard gold, USD or buy other assets. In the settings of an unstable economy, monetary values and purchasing power of the currency are seriously fluctuating, thus, people tend to accumulate gold, USD or other valuables, instead of depositing their savings at commercial or state-owned banks.

Conversely, if an economy is developing stably and demonstrates a reasonable inflation rate, people have more confidence, therefore, deposits in commercial banks become more popular. This means that public regulations authors and the central bank in the first place (as the principal regulator) have to come up with the right policies to attract and maintain deposits from private clients (population).

Individual savings deposit is a deposit made by a resident into a savings account at a commercial bank (or similar institution) to accumulate profit and ensure assets' safety. The ability to mobilize residential capital is one of the most important measures to assess the size, capability and reputation of commercial banks, and Vietnamese financial market is no exception in this regard.

Residential deposits are rather uncomplicated in terms of organization and procedures, which means that all commercial banks are able to offer personal savings products. And this, in turn, means that competitive pressure in this segment is always growing. Private customers who deposit savings are always driven by a rational choice, which is the profitability of savings deposit as compared to other savings. At the same time, investment channels are not comparable due to much higher risk level.

The issue of customer loyalty is still an open research field as this phenomenon is approached to in many dissimilar ways. According to Barroso, C. \& Picón, A. (2012) customer dedication is a commitment to buy again or revisit a favorite product or service in the future, to make repeated purchases of the same brand. Loyalty is also seen as a commitment of customers to buy their favorite product or service.

Customers always prioritize to buy a certain product in the future. In banking and other fiscal services, customer loyalty towards certain products and services is consistent with bank brand loyalty. Brand loyalty has been considered by many writers in the context of customer behavior (Pérez \& Del Bosque, 2015; Kassim \& Abdullah, 2010).

Therefore, commercial banks need to pay more attention to preserving customer loyalty to a bank brand and this should be incorporated into bank's strategic marketing planning process (Bahareh Moradi Aliabadi et al., 2013). Some authors consider the impact of component groups on customer commitment (Jamal \& Naser, 2002).

Some of the factors included into that analysis as directly affecting brand loyalty included: Quality of service, reputation, belief, habits, satisfaction, conversion costs, price.

\section{Literature Review}

\section{Business brand and bank brand}

The American Marketing Association defines a brand as "name, term, symbol or design, or a combination thereof to identify and distinguish the goods or services of one or a group of sellers from the competitors' products and services". 


\section{SATISFACTION WITH BANK BRANDS}

Our survey treats trademark as a distinguishing aspect of trade name, thus, impact means brand's impact on consumers' minds, the influence on the attitude and behavior of consumers. Financial services belong to the service industry, thus, there is no packaging, tagging and product display involved. In this context, brand value is perceived and understood by consumers in a very different (as compared to tangible products) way (Goldring, 2015). Brand elements here are directly associated with the elements of the service space, both tangible and intangible, including: facilities, people (staff, other customers), the implementation processes etc. (Jamal, 2007).

\section{Individual customers' deposit savings}

Individual customers who deposit money are individuals or households that have personal deposit at commercial banks or other credit institutions. In the study they are referred to as "subjects". Commercial banks are always in need of some sort of a basic customer base to develop diversified and cross-selling products (Kassim \& Abdullah, 2010). Saving deposits of individual customers overall stand for all the amounts of individual customers deposited into the savings deposit accounts provided by the bank, while the primary aim for individual customers would be enjoying the interest rate as assigned by the receiving organization.

\section{Behavioral characteristics of individual customers of the savings deposits}

The behavior of individual customers interested in depositing savings at commercial banks can be classified according to the time factor and other parameters of the personal consumption behaviors (Jamal \& Naser, 2002). As per time specifically the behavior can be classified as follows: Behavior before deposit, Behavior in the deposit process, Behavior after deposit and finally, Future behavior.

\section{Loyalty to bank brand}

Commitment is an significant concept in marketing management and behavioral psychology. When clients have loyalty to a particular brand, they have less grounds to seek information on how to replace a product or a service (thus replacing that brand). Brand loyalty is usually approached at three levels: (1) Behavioral loyalty; (2) Loyalty attitude; (3) Loyalty combining both behavior and posture.

According to (Ai Huu Tran, 2017) behavioral loyalty could be best researched through the random survey of many clients. According to (Barroso \& Picón, 2012), loyalty implies customer awareness and attitudes towards a specific service product.

\section{Customer satisfaction as applied to retail banks}

Customers of retail banks with favorable perceptions of service quality usually demonstrate higher satisfaction. Customer satisfaction mediates the impact of service quality on customer loyalty (Pérez \& Del Bosque, 2015).

\section{Research model and hypotheses}


Based on the abovementioned general analysis of the factors affecting brand loyalty of bank customers, the author chooses to approach the research model of some factors affecting brand loyalty through intermediary variables.

The initial hypotheses as per the research model are formulated as follows:

H1: Overall service quality positively affects customer satisfaction.

$\mathrm{H} 2$ : Brand reputation positively affects customer satisfaction.

H3: Social responsibility positively affects customer satisfaction.

H4: Customer satisfaction positively affects customer brand loyalty.

H5: Conversion costs impact on transition from customer satisfaction to brand loyalty.

H6: Commitment in the relationship affects the transition from customer satisfaction to brand loyalty.

\section{Research method}

Our core research method here is survey. The sample covered 356 customers living in the HCM City. The sample consists of the individual customers with depositing savings at various commercial banks.

They take on a great deal of knowledge and experience with the banking brands currently present on Vietnamese market.

The sample was selected using the convenient sampling method based on individual referrals, in some cases. The respondents have been answering questions keeping in mind the brand of the bank they were then using.

Table 1 - Descriptive statistics of the research sample (made by the authors)

\begin{tabular}{|c|c|c|c|}
\hline \multicolumn{2}{|c|}{ Parameters } & \# of answers & $\%$ \\
\hline \multirow{4}{*}{$\begin{array}{c}\text { Time of their first } \\
\text { deposit }\end{array}$} & Less than a year & 109 & 31 \\
\hline & From 1 to less than 2 years & 165 & 46 \\
\hline & From 2 to less than 3 years & 35 & 10 \\
\hline & 3 years and more & 47 & 13 \\
\hline \multirow{4}{*}{$\begin{array}{c}\text { Number of banks } \\
\text { used }\end{array}$} & 1 bank & 221 & 62 \\
\hline & 2 banks & 84 & 24 \\
\hline & 3 banks & 27 & 8 \\
\hline & Over 3 banks & 24 & 7 \\
\hline \multirow{5}{*}{ Timing of a deposit } & Indefinite time & 17 & 5 \\
\hline & For less than 1 month & 38 & 11 \\
\hline & 4-6 months & 37 & 10 \\
\hline & 7-12 months & 68 & 19 \\
\hline & Over 12 months & 196 & 55 \\
\hline \multirow{2}{*}{$\begin{array}{c}\text { The use of additional } \\
\text { bank services in the } \\
\text { same bank }\end{array}$} & Yes & 272 & 76 \\
\hline & No & 84 & 24 \\
\hline
\end{tabular}




\section{SATISFACTION WITH BANK BRANDS}

First, the scales will be preliminarily assessed through two methods: Cronbach's Alpha reliability coefficient and evolving factor analysis (EFA). Next, the scales are verified by means of confirmatory factor analysis (CFA) method.

\section{Evolving Factor Analysis (EFA)}

The results of this part of our analysis show that 27 observed variables in 7 components of the bank brand loyalty scale maintained 7 factors with 27 observed variables. KMO coefficient $=0.755$, so EFA is consistent with the data and the Chi-quare statistics of Bartlett's test is reaching 5683,707 with the significance level of 0.000 .

This means that the observed variables are correlated with each other as a whole. The variance extracted by 72,431 shows that the 7 factors extracted are explained by $72,431 \%$ of the variation in data, at a separate coefficient of value of 1,802 .

Therefore, the scale drawn is acceptable.

Table 2 - Summary on reliability and total variance (made by the authors)

\begin{tabular}{|c|c|c|c|c|c|}
\hline No & Measurement & $\begin{array}{l}\text { Observed } \\
\text { variables }\end{array}$ & $\begin{array}{l}\text { Reliability } \\
\text { coefficient }\end{array}$ & $\begin{array}{c}\text { Total variance } \\
\text { extracted }\end{array}$ & Conclusion \\
\hline 1 & Loyalty & 3 & 0,884 & $81,64 \%$ & \multirow{7}{*}{$\begin{array}{l}\text { The scales } \\
\text { are reliable }\end{array}$} \\
\hline 2 & Overall service quality & 4 & 0,876 & $72,90 \%$ & \\
\hline 3 & Satisfaction & 3 & 0,763 & $68,12 \%$ & \\
\hline 4 & Conversion costs & 4 & 0,880 & $74,41 \%$ & \\
\hline 5 & $\begin{array}{l}\text { Commitment from the } \\
\text { relationship }\end{array}$ & 3 & 0,934 & $88,44 \%$ & \\
\hline 6 & Brand reputation & 5 & 0,885 & $59,77 \%$ & \\
\hline 7 & Social responsibility & 5 & 0,867 & $65,84 \%$ & \\
\hline
\end{tabular}

\section{Confirmatory factor analysis (CFA)}

Regarding general suitability, the analysis shows that this model has the statistical value of squared chi $=354,669$ with 233 degrees of freedom $(p=0,000)$. The relative square root of the degrees of freedom CMIN / df is 1,522 $(<0.2)$. Other indicators such are: GLI = $924(0.9), \mathrm{TLI}=0.970(>0.9), \mathrm{CFI}=0.974(>0.9)$ and $\mathrm{RMSEA}=0.038(<0.08)$. 


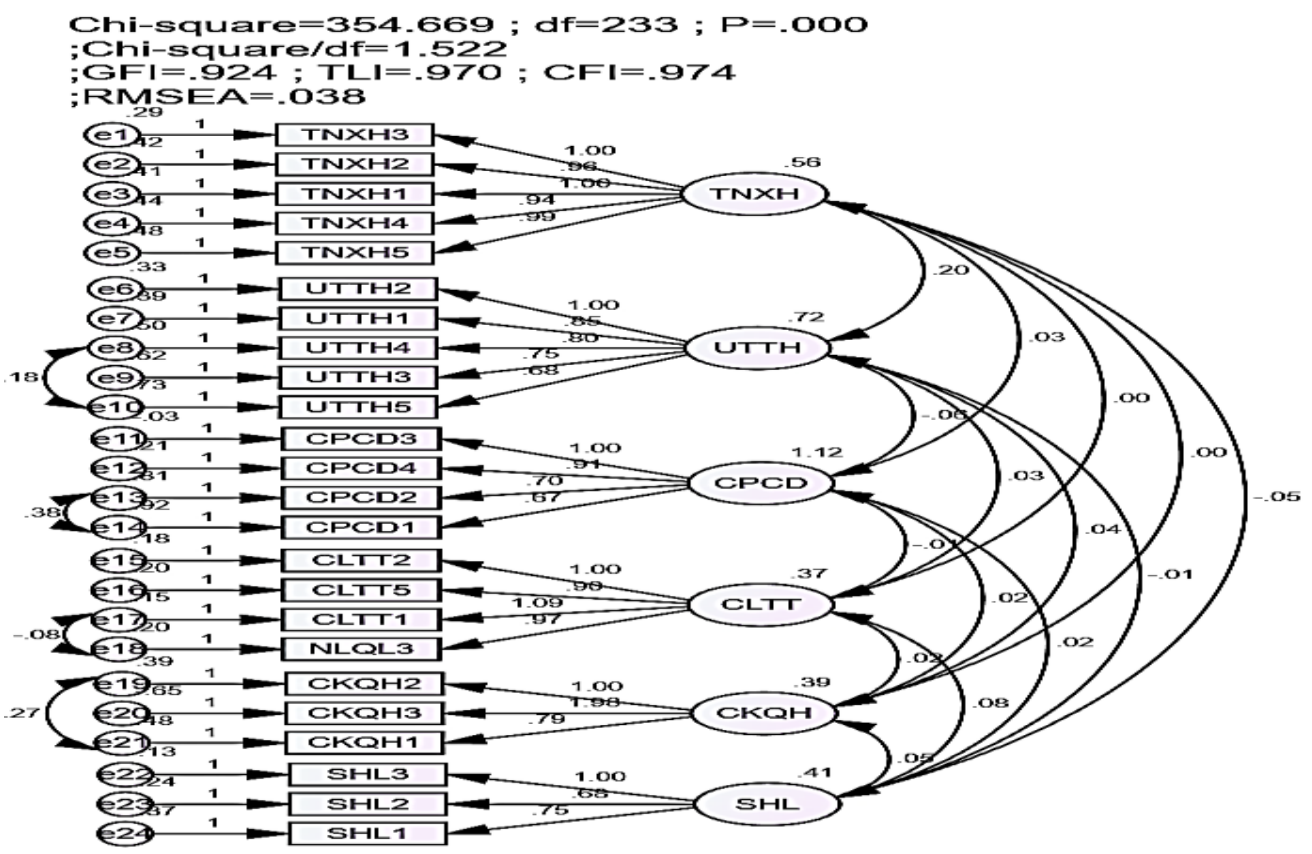

Figure 1 - CFA results

(Source: Authors' own calculations in SPSS 23.0)

This makes our model and results suitable for market research. This also permits us to make further statements about the unidirectionality of the observed variables. Regarding the convergence value, the standard weights of the scales are $>0.5$ and have the statistical significance of $\mathrm{p}<0.5$. Therefore, the scales achieve the convergent values.

\section{Structural equation modeling (SEM)}

There are 7 research concepts used in our research model, including 3 independent concepts: overall quality, brand reputation, and social responsibility; 2 regulatory concepts are conversion costs and relationship commitments. In contrast, the two dependent concepts are satisfaction and brand loyalty.

The results show that the structural model has the square root statistical value of 447,446 with 276 degrees of freedom $(\mathrm{p}=0,000)$. The square root of the relative to the degrees of freedom CMIN / df is $1.642(<0.2)$. Other indicators are as follows: GLI $=0.912$ $(0.9), \mathrm{TLI}=0.962(>0.9), \mathrm{CFI}=0.968(>0.9)$ and RMSEA $=0.042(<0.08)$. This makes the model compatible. And this also means that we are accepting all our initial hypotheses $(\mathrm{H} 1$, $\mathrm{H} 2, \mathrm{H} 3, \mathrm{H} 4, \mathrm{H} 5$ and $\mathrm{H} 6$ ). 


\section{SATISFACTION WITH BANK BRANDS}

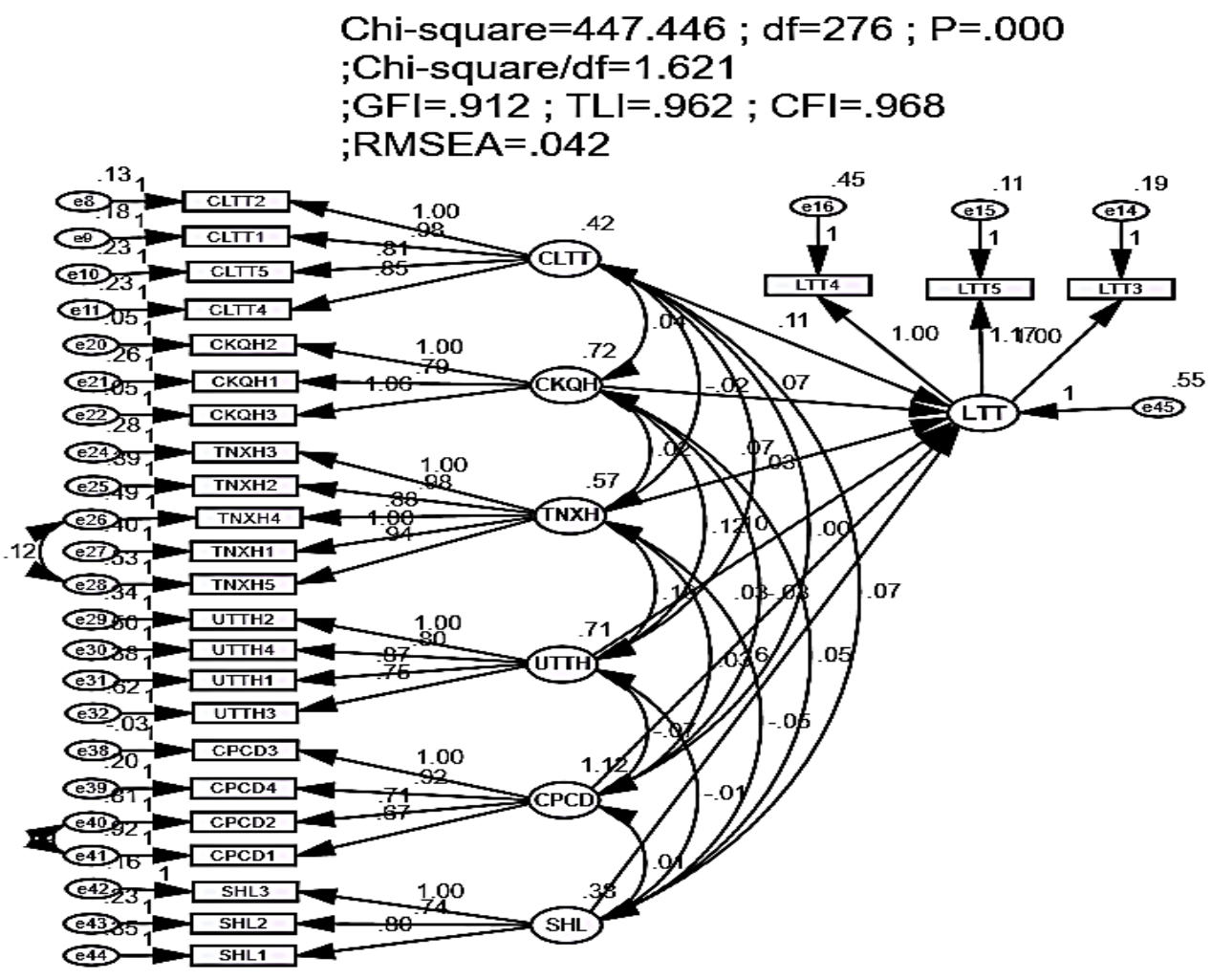

Figure 3 - Results of the calibrated SEM.

(Source: Authors' own calculations in SPSS 23.0)

\section{Results' discussion and directions for further research}

The research results support the research model, including the components of brand reputation, overall quality and social responsibility. Satisfaction is a dependent variable here, with two moderating variables, both helping customers to engage with the bank for longer. The results of Cronbach's alpha, EFA and CFA analyses show that the achieved scale is reliable. On the other hand, the research has also produced a structural equation model (SEM) that measures 6 components. The results of our research might be useful for those working with brand promotion of commercial banks in Vietnam.

The analytical results show that satisfaction has a direct and strong impact on brand loyalty of customers. To improve customer satisfaction requires commercial banks monitor synchronously the elements that together constitute customer satisfaction. The study offers a number of recommendations for commercial banks to improve customer satisfaction through such factors as service quality, brand reputation, and social responsibility.

Despite the best endeavors, due to limited time, the sample used in this study was not big enough and did not cover the whole country, only the capital city. Besides that, there can be other elements also affecting customer loyalty to a brand of a particular bank, such as specificity of a region, culture, habits in money use etc. These factors have been overlooked in our analysis. 


\section{References:}

Ai Huu, T. (2017). Environmental impacts on small and medium enterprise effectiveness (the case of the fisheries sector in Vietnam). The EUrASEANs: journal on global socioeconomic dynamics, 2 (4).

Bahareh Moradi, A. et al. (2013). Design and explain the factors affecting customer loyalty in online banking. International Research Journal of Applied and Basic Sciences, 4(9), 2782-2791.

Barroso, C. \& Picón, A. (2012). Multi-dimensional analysis of perceived switching cost. Industrial Marketing Management, 41(3), 531-543.

Goldring, D. (2015). Reputation orientation: Improving marketing performance through corporate reputation building. Marketing Intelligence \& Planning, 33(5), 784-803.

Jamal, A. (2007). Retail banking and customer behaviour: a study of self concept, satisfaction and technology usage. The International Review of Retail, Distribution and Consumer Research, 14(3), 357-379.

Jamal, A. \& Naser, K. (2002). Customer satisfaction and retail banking: an assessment of some of the key antecedents of customer satisfaction in retail banking. International Journal of Bank Marketing, 20(4), 146-160.

Kassim, N. \& Abdullah, N.A. (2010). The effect of perceived service quality dimensions on customer satisfaction, trust, and loyalty in e-commerce settings: a cross-cultural analysis. Asia Pacific Journal of Marketing and Logistics, 22(3), 351-71.

Pérez, A., \& Del Bosque, I. (2015). Customer responses to the CSR of banking companies. Journal of Product \& Brand Management, 2(5), 481-493.

Paper submitted

Paper accepted for publishing

Paper published online
12 March 2020

11 May 2020

O2 June 2020 